\title{
A comparative molecular approach to mesodermal patterning in basal deuterostomes: the expression pattern of Brachyury in the enteropneust
} hemichordate Ptychodera flava

\author{
Kevin J. Peterson ${ }^{1,2}$, R. Andrew Cameron ${ }^{1}$, Kunifumi Tagawa ${ }^{3, *}$, Noriyuki Satoh ${ }^{3}$ and Eric H. Davidson ${ }^{1, \neq}$ \\ ${ }^{1}$ Division of Biology, California Institute of Technology, Pasadena, CA 91125, USA \\ 2Division of Geological and Planetary Sciences, California Institute of Technology, Pasadena, CA 91125, USA \\ 3Department of Zoology, Graduate School of Science, Kyoto University, Kyoto 606-8502, Japan \\ *Current address: Kewalo Marine Laboratory, Pacific Biomedical Research Center, University of Hawaii, 41 Ahui Street, Honolulu, HI 96813-5511, USA \\ ‡Author for correspondence (e-mail: davidson@mirsky.caltech.edu) \\ Accepted 16 October; published on WWW 3 December 1998
}

\section{SUMMARY}

This work concerns the formation of mesoderm in the development of an enteropneust hemichordate, Ptychodera flava, and the expression of the Brachyury gene during this process. Brachyury expression occurs in two distinct phases. In the embryo, Brachyury is transcribed during gastrulation in the future oral and anal regions of the gut, but transcripts are no longer detected by 2 weeks of development. Brachyury expression is not detected during the $\mathbf{5}$ months of larval planktonic existence. During this time, the adult coeloms begin to develop, originating as coalescences of cells that appear to delaminate from the wall of the gut. Brachyury expression cannot be detected again until metamorphosis, when transcripts appear in the mesoderm of the adult proboscis, collar and the very posterior region of the trunk. It is also expressed in the posterior end of the gut. At no time is Brachyury expressed in the stomochord, the putative homologue of the chordate notochord. These observations illuminate the process of maximal indirect development in Ptychodera and, by comparison with patterns of Brachyury expression in the indirect development of echinoderms, their sister group, they reveal the evolutionary history of Brachyury utilization in deuterostomes.

Key words: Brachyury, Hemichordate, Evolution, Mesoderm, Notochord, Ptychodera flava

\section{INTRODUCTION}

Most animals are classified as bilaterians and, in addition to the obvious change in symmetry properties, a hallmark of the evolutionary process that led to the bilaterians was the appearance of mesodermal structures. Mesoderm is integral to the construction of all modern bilaterian body plans. In the process of development, mesoderm is a frequent source of inductive signals; for example, in vertebrates the notochord is involved in patterning all three body axes (Danos and Yost, 1996) and also induces the development of other organs (e.g., pancreas; Kim et al., 1997). Mesodermal derivatives also constitute major components of the bilaterian body plan (Ruppert and Barnes, 1994). They define the grade of body plan organization, i.e., whether the animal is coelomate, pseudocoelomate or acoelomate. Furthermore, cell types, such as blood cells and muscle cells, and organs, such as nephridia, which are not found in sponges and cnidarians, arise from mesoderm. Finally, mesoderm conveys a third dimension to the animal's body plan with the attendant requirements for internal organization; animals that lack mesoderm are effectively 'two-dimensional' such that almost every cell is in direct contact with the ambient sea water.
We have begun a series of investigations on the origin and specification of mesoderm in basal deuterostomes. The deuterostomes comprise three monophyletic phyla: the echinoderms, the chordates and a third, lesser-known group, the hemichordates. Hemichordates consist of two subgroups, pterobranchs and acorn worms or enteropneusts. Recent phylogenetic investigations using 18S rDNA (e.g., Turbeville et al., 1994; Wada and Satoh, 1994; Eernisse, 1997) and mitochondrial codon usage (Castresana et al., 1998) suggest that, contrary to previous morphological analyses (e.g. Peterson, 1995), echinoderms and hemichordates are each other's closest relative (i.e., they are sister taxa).

Both enteropneusts and echinoderms undergo what we have termed 'maximal indirect development' (Davidson et al., 1995; Peterson et al., 1997; Cameron et al., 1998) whereby an elegant but simple larval stage precedes the development of the adult body plan. This is in contrast to the developmental mode found in chordates. Chordates are all direct developers and thus establish the adult body plan immediately without any intervening primary larval stage (see also Nielsen, 1998). The adult body plan of maximal indirect developers arises from groups of cells that are 'set-aside' from participation in the 
construction of the embryo/larva. In enteropneusts and echinoderms, endomesodermal set-aside cells produce the tripartite coeloms from which the mesodermal components of the adult body plan arise. These are the anterior coelom or protocoel, paired middle coeloms or mesocoels and paired posterior coeloms or metacoels; these coeloms are called the axocoels (paired in echinoderms), hydrocoels and somatocoels, respectively, in echinoderms. The remarkable similarity in structure of hemichordate and echinoderm larval coeloms (Peterson et al., 1997) is an obvious and significant synapomorphy of these groups.

Brachyury, the canonical member of the 'T-box' family of transcription factors, is intimately tied to mesoderm specification in vertebrates (recent reviews include Herrmann and Kispert, 1994; Herrmann, 1995; Kavka and Green, 1997; Papaioannou, 1997; Smith, 1997; Papaioannou and Silver, 1998). The pattern of Brachyury gene expression is highly conserved amongst vertebrates. Brachyury is initially expressed pan-mesodermally, but is downregulated in paraxial mesoderm cells as they move through the primitive streak or equivalent. As development continues, Brachyury becomes restricted to the notochord, and the posterior mesoderm and gut. Several lines of evidence suggest that Brachyury is necessary for the proper specification of the notochord and posterior mesoderm. (1) The Brachyury mutation in mouse ( $T$; Herrmann et al., 1990) and in zebrafish ( $n t l$; Schulte-Merker et al., 1994) results in the absence or reduction of posterior mesoderm and notochord, the same tissues that express the Brachyury message and protein (Wilkinson et al., 1990; Schulte-Merker et al., 1992; Kispert and Herrmann, 1994). Correspondingly, the phenotype of Brachyury mutations in mouse can be rescued by a transgene of the wild-type $T$ allele (Stott et al., 1993). (2) Studies by Kispert et al. (1995) and Conlon et al. (1996) have shown that Brachyury functions as a transcriptional activator. Not only do several $n t l$ mutations lack this activation domain, but replacing the activation domain of Xbra (the Xenopus Brachyury orthologue) with the engrailed repressor domain results in phenotypes similar to the naturally occurring mutants. A normal function of Brachyury during vertebrate gastrulation is apparently to activate transcription of mesoderm-specific genes (Conlon et al., 1996). (3) Expression of Brachyury occurs as a result of mesoderm induction (Smith et al., 1991; Ding et al., 1998), possibly as an immediate-early response (Smith et al., 1991; Tadano et al., 1993; Knezevic et al., 1997). (4) Injecting Brachyury protein into animal caps induces mesodermal cell types (Cunliffe and Smith, 1992) in a concentration-dependent manner (O'Reilly et al., 1995). (5) Cis-regulatory elements in the promoter region of the Brachyury gene have been identified that drive reporter expression in the posterior mesoderm of mouse (Clements et al., 1996) and frog (Latinkić et al., 1997) and in the notochord of ascidians (Corbo et al., 1997).

Brachyury orthologues were earlier cloned from both sea urchins (Harada et al., 1995) and hemichordates (see Tagawa et al., 1998a for sequence and phylogenetic analysis). However, these studies were focused solely on Brachyury expression during embryogenesis, and nothing whatsoever was known about expression of this gene in the postembryonic processes by which the mesoderm of the respective adult body plans arises from the mesodermal set-aside cells of the embryo. We have now determined the pattern of Brachyury expression in the adult rudiment of a sea urchin larva (K. J. P., unpublished data) and in the larval and metamorphic stages of Ptychodera flava, as described below. Furthermore, very little is known about the formation of the adult mesoderm in indirectly developing enteropneusts; prior observations are limited primarily to Morgan (1891, 1894), and no modern paper has dealt with the ontogeny of the adult enteropneust coeloms (Hadfield, 1975; see Fig. 1 for the description of these structures). Thus our goals are twofold: First, to ascertain the developmental origin of the adult coeloms of P. flava and, second, to examine the expression pattern of Brachyury throughout its process of maximal indirect development, i.e., from the early tornaria larva through metamorphosis and establishment of the adult body plan.

\section{MATERIALS AND METHODS}

\section{Collection of larvae and culture of embryos and larvae}

Adult gravid worms were collected near Diamond Head, Honolulu, Hawaii and shipped overnight to Caltech's Kerckhoff Marine Laboratory (Corona del Mar, CA). Ripe animals placed at room temperature in glass dishes with sand spawned naturally within 24 hours of arrival. Eggs were fertilized, washed twice in sea water and allowed to develop for several days at $25^{\circ} \mathrm{C}$. Larvae were transferred to eight-liter containers at a concentration of 1 per ml sea water with constant, slow stirring. Initially, the larvae were fed a mixture of algae consisting of Dunaliella tertiolecta, Pavlova sp. and Phaeodactylum tricornutum (Strathmann and Bonar, 1976) at about 3000 cells per ml sea water. However, after about 1 month of development, the animals appeared to have stopped growing. We then replaced the previous algal mixture with Rhodomonas lens at 3000 cells per $\mathrm{ml}$ sea water and renewed growth of the larvae was immediately apparent. The water was changed once a week and the animals fed once or twice a week depending on clearance rate. The larvae were cultured in this fashion for the next 6 months.

Competent larvae were obtained following the methods of Hadfield (1978). Plankton tows were conducted off Kewalo Marine Laboratory, University of Hawaii, Honolulu, at about $10 \mathrm{~m}$ depth using a net with a mesh size of $200 \mu \mathrm{m}$. Plankton was brought into the laboratory and competent $P$. flava larvae, which are easily recognized by the development of the proboscis and the large anal region posterior of the telotroch (see Fig. 5A), were isolated from other plankton under a dissecting scope. Most of the larvae collected could be confidently attributed to $P$. flava based on the developmental time table (Hadfield, 1975,1978 ) and the existence of at most only two other species of enteropneust in the area (Edmondson, 1946). We did collect two specimens of another type of enteropneust which did not hybridize with the PfBra probe (data not shown). Competent $P$. flava larvae that were not fixed immediately (see below) were placed in a plastic Petri dish with a monolayer of freshly collected sand. By 24 hours, the animals had completed metamorphosis to the extent that a collar-trunk distinction was apparent (see Fig. 5C). The water was changed daily and the worms were fixed on 24 hour intervals for 3 days.

\section{DNA probe isolation}

A 370 base pair (bp) fragment of the PfBra cDNA (Tagawa et al., 1998a), which lies between a SacI site (+352 from the start codon) and a MfeI site $(+722)$, was isolated and cloned into pBS II SK+ (Stratagene) that had been double digested with $S a c I$ and EcoRI. An antisense riboprobe was made by linearizing the construct at the $5^{\prime}$ end with SacI, removing the $3^{\prime}$ overhang with T4 DNA polymerase and synthesizing the riboprobe with $\mathrm{T} 7$ following instructions of the manufacturer (Boehringer Mannheim DIG RNA labeling kit). The sense riboprobe was made after linearization at the $3^{\prime}$ end of the construct with KpnI.

A cytoplasmic actin coding probe previously isolated from $P$. flava (M. Kobayashi and N. S., unpublished data) was used as a positive control. Approximately $1.2 \mathrm{~kb}$ of the actin gene had been cloned into 
pBS II SK+. The template was prepared by excision of a $\sim 1 \mathrm{~kb}$ SmaIEcoRV fragment and religation of the vector with the remaining 240 bp of the actin fragment. The antisense riboprobe was synthesized after linearization at the $5^{\prime}$ end of the insert with BamHI.

\section{Genomic Southern blot analysis}

High molecular weight sperm DNA simultaneously collected from several individuals was digested exhaustively in separate reaction mixtures with EcoRI, EcoRV, HindIII, SpeI or XbaI. $15 \mu \mathrm{g}$ of digested DNA were resolved by agarose gel electrophoresis, depurinated for 30 minutes in $0.2 \mathrm{~N} \mathrm{HCl}$, denatured $2 \times 15$ minutes in $1.5 \mathrm{M} \mathrm{NaCl}, 0.5 \mathrm{M}$ $\mathrm{NaOH}$, and transferred to Hybond $\mathrm{N}+$ nylon membrane (Amersham) using a TURBOBLOTTER (Schleicher \& Schuell) with $0.4 \mathrm{M} \mathrm{NaOH}$. The 370 bp SacI-MfeI fragment was random labeled with $\left[{ }^{32} \mathrm{P}\right] \mathrm{dCTP}$ (Pharmacia). Hybridization was done at $60^{\circ} \mathrm{C}$ overnight with the buffer of Church and Gilbert (1984) and washed under high stringency conditions $\left(2 \times \mathrm{SSC}, 0.2 \%\right.$ SDS $1 \times 30$ minutes at $60^{\circ} \mathrm{C} ; 0.2 \times \mathrm{SSC}, 0.2 \%$ SDS $2 \times 30$ minutes at $60^{\circ} \mathrm{C}$ ). The blot was exposed for about 8 hours.

To determine if the two bands in the EcoRI, EcoRV and HindIII lanes are due to allelic variation or to the presence of the respective sites in an intron (intron 3 of Wattler et al., 1998), PCR primers were designed to amplify the cDNA probe region in an isolated lambda clone containing the PfBra gene (K. J. P., unpublished data): forward primer: 5'-GTCTATATCCACCCAGAC3'; reverse primer: 5'-GTACATCGTGAGCATGGG-3'. A $2 \mathrm{~kb}$ fragment was amplified using standard PCR parameters and digested with EcoRI, EcoRV, or HindIII. Both the EcoRV and HindIII digests gave two bands; the EcoRI digest did not.

\section{Fixation and in situ hybridization}

Larvae and embryos were fixed in $2.5 \%$ glutaraldehyde, $0.24 \mathrm{M} \mathrm{NaCl}, 0.1 \mathrm{M} \mathrm{PO}_{4}$ buffer, $\mathrm{pH} 7.4$, for 4 hours on ice; washed in $0.4 \mathrm{M} \mathrm{NaCl}, 0.1 \mathrm{M} \mathrm{PO}_{4}$ buffer, $\mathrm{pH} \mathrm{7.4,}$ $2 \times 5$ minutes, and dehydrated to $70 \%$ EtOH. The field-collected competent larvae and juveniles were cleared in xylene. In situ hybridization followed the protocol of Holland et al. (1996) with the following changes: (1) embryos and larvae were digested in $7.5 \mu \mathrm{g} / \mathrm{ml}$ proteinase $\mathrm{K}$ for 5 minutes, competent larvae, 24- and 48-hour juveniles were digested for 20 minutes, 72 -hour juveniles for 25 minutes; (2) anti-digoxigenin antibody was diluted to $1: 5000$ and preabsorbed with Ptychodera flava adult powder (preabsorption is necessary because the anti-digoxigenin antibody crossreacts with a muscle-specific epitope even in the absence of a riboprobe); (3) after removal of the antibody and washing in NaPBST $4 \times 20$ minutes, the animals were washed twice in AP buffer, $\mathrm{pH}$ 8.0, before the AP pH 9.5 wash (see Ransick et al., 1993); (4) the staining solution consisted of $4.5 \mu \mathrm{l}$ of $75 \mathrm{mg} / \mathrm{ml}$ NBT, 3.5 $\mu l \quad 50 \mathrm{mg} / \mathrm{ml}$ BCIP and $1 \mu \mathrm{l} \quad 1 \quad \mathrm{M}$ levamisole in $1 \mathrm{ml} \mathrm{AP} \mathrm{pH} 9.5$ buffer. Staining was apparent after 1 hour with competent larvae and juveniles, overnight with embryos and 1-week larvae. The reaction was stopped with $1 \mathrm{mM}$ EDTA in NaPBST.

\section{Mounting, sectioning and photography}

Specimens were photographed using a ProgRes 3012 high-resolution digital color camera (Kontron Elektronik, $\mathrm{GmbH}$ ) mounted on either a Zeiss Axioskop microscope equipped with DIC optics or a Zeiss dissecting microscope. To facilitate photography of live larvae, the animals were anesthetized in $10 \mathrm{mM}$ sodium azide in sea water. Whole-mount in situ specimens were cleared in a graded series of glycerol solutions to $50 \%$ and then photographed. Competent larvae and juveniles were rehydrated and then dehydrated in a graded series of ethanol solutions to $100 \%$. They were then transferred to Histosol (National Diagnostics) and embedded in paraffin wax. $15 \mu \mathrm{m}$ sections were cut, mounted in immersion oil and photographed using a digital camera. Images were recorded using Wincam v.1.4 (Roche, Charlotte) and processed using Adobe Photoshop v.4.0.

\section{RESULTS}

\section{PfBra is a single-copy gene}

Because we are examining a discontinuous pattern of expression (see below), it was important to determine if Brachyury is a single-copy gene in P. flava. Using a genomic

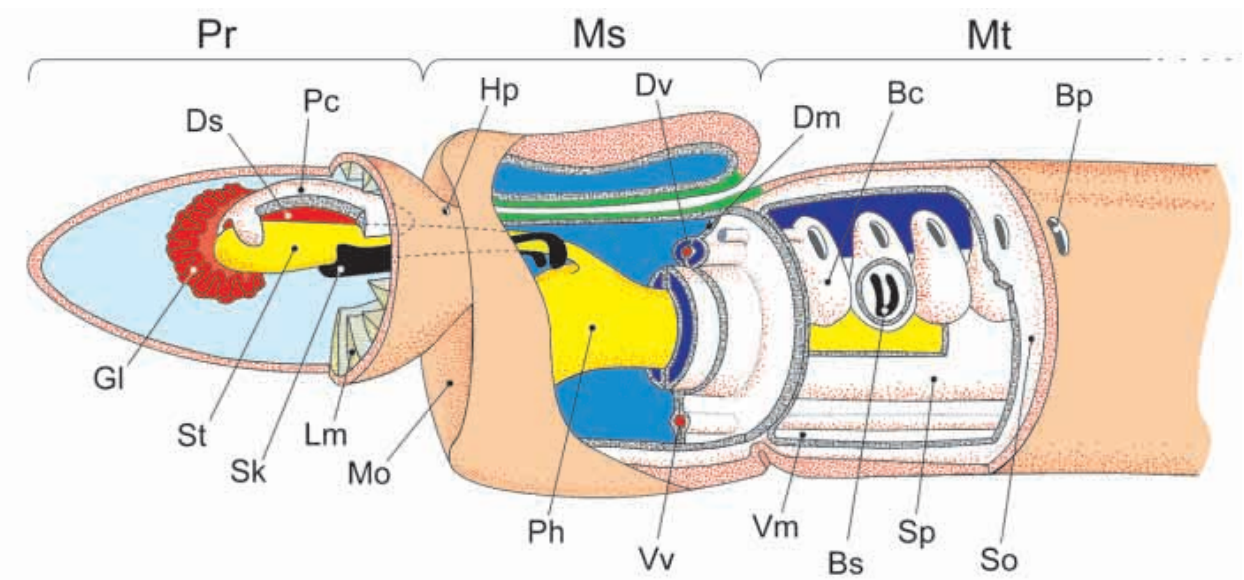

Fig. 1. Generalized anatomy of an enteropneust hemichordate. The body of an enteropneust is divided into three regions. Each body cavity or coelom, shaded in blue, is lined by mesoderm (So, somatopleura or outer lining; Sp, splanchnopleura or inner lining). The most anterior region is the proboscis or protosome (Pr) whose coelomic cavity, the protocoel, is shown in light blue. Immediately behind the proboscis is the collar or mesosome (Ms), which has a pair of cavities called the mesocoels (shown in medium blue). The rest of the body consists of the trunk or metasome (Mt) whose coelomic cavities are called the metacoels (dark blue). To see the coelomic spaces, the longitudinal musculature $(\mathrm{Lm})$ of the proboscis, and the dorsal $(\mathrm{Dm})$ and ventral mesenteries $(\mathrm{Vm})$ of the collar are cut-away; the dorsal mesentery of the trunk is not shown. The outer ectoderm is shown in beige, the gut in yellow, the dorsal hollow nerve cord (or collar cord) in green, and elements of the circulatory and excretory systems are in red. The stomochord (St), the putative homologue of the chordate notochord, is the anterior projection of the dorsal wall of the pharynx $(\mathrm{Ph})$. The stomochord is an integral component of the axial complex, the head kidney or metanephridium of the adult worm (Balser and Ruppert, 1990). It serves as a supporting element for the pericardium $(\mathrm{Pc})$ whose contractions drive blood from the dorsal sinus (Ds), a continuation of the dorsal vessel (Dv). From the dorsal sinus, the blood enters the glomerulus (Gl) where it is filtered. The urine thus formed is released into the protocoel and then, after modification, it exits the body via the hydropore (Hp). Blood returns to the body through the ventral blood vessel (Vv). The stomochord and its underlying skeleton (Sk, shown in black), a thickened basement membrane, also serve to strengthen the connection between the proboscis and collar. Also of phylogenetic import are the U-shaped branchial slits (Bs) which show considerable similarity to the pharyngeal slits of chordates (Pardos and Benito, 1988; Nielsen, 1995). Water enters the gut through the mouth (Mo), and is able to pass from the gut through the U-shaped slits into the branchial sacs $(\mathrm{Bc})$ and exit via the branchial pores $(\mathrm{Bp})$. Note that for simplicity many structures are not indicated including most of the nervous system, circulatory system, and musculature. Redrawn from Balser and Ruppert (1990) and Benito and Pardos (1997). 
Southern blot probed at high stringency with the same cDNA sequence as used for the whole-mount in situ hybridization (WMISH), we determined that, of five enzymes examined, two produced single fragments and three produced two fragments that reacted with the Brachyury probe (Fig. 2). Restriction digests of the probed region from a genomic lambda clone (see Materials and Methods) showed that the two bands in the EcoRV and HindIII lanes are due to the presence of the respective restriction sites within the probed intron (data not shown), whereas the two bands in the EcoRI lane are due to the heterozygous occurrence of restriction sites outside the probed region. These data indicate that the Ptychodera flava Brachyury gene (PfBra) occurs in a single copy per haploid genome. Therefore, the discontinuous expression pattern discussed below is not due to the differential regulation of two paralogues.

\section{Early development and embryonic spatial expression pattern of PfBra}

Both the early embryology of P. flava (Rao, 1954; Hadfield, 1975; Tagawa et al., 1998b) and the embryonic spatial expression pattern of PfBra (Tagawa et al., 1998a) have been discussed elsewhere. The salient points are as follows. By 24 hours of development, the embryo is in the process of gastrulating and an outpocketing of mesoderm from the tip of the archenteron is now readily apparent (Fig. 3A). This mesoderm with its enclosed cavity, the protocoel, will initially form part of the larval protonephridium (Fig. 3C), and later the mesoderm of the adult proboscis. WMISH of PfBra at these

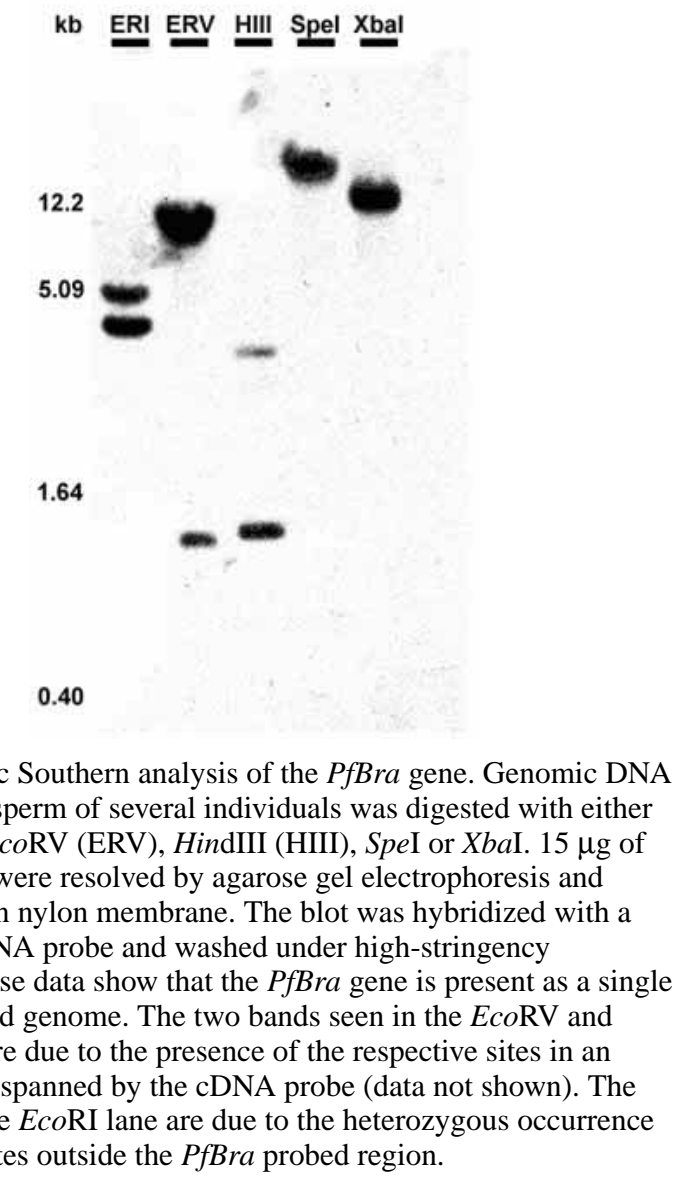

stages confirmed exactly the pattern reported by Tagawa et al. (1998a). PfBra expression is limited to the oral and anal regions of the embryonic gut (Fig. 3B,D). At no time is PfBra expressed in any component of the embryonic mesoderm. By 2 weeks of development PfBra can no longer be detected by WMISH (data not shown; Tagawa et al., 1998a).

\section{Larval development}

The 1-week tornaria larva (Fig. 3C; Hadfield, 1975; Tagawa et al., 1998a) is equipped with both a feeding ciliated band and a locomotory ciliated band called the telotroch. The gut is clearly tripartite with an esophagus, stomach and intestine. There is an apical plate with a ciliated tuft and two eye spots (not visible in Fig. 3C but shown in the older larvae of Fig. 4). The axes of the larva are identical to that of the adult: the apical/anal axis is equivalent to the anterior/posterior axis of the adult with the eye spots visible at the tip of the proboscis during the initial stages of metamorphosis, the larval mouth, which is continuous with the adult mouth, is located ventrally, and the hydropore dorsally. The embryonic mesoderm has formed the proximal region of the protocoelomic duct, which connects to the
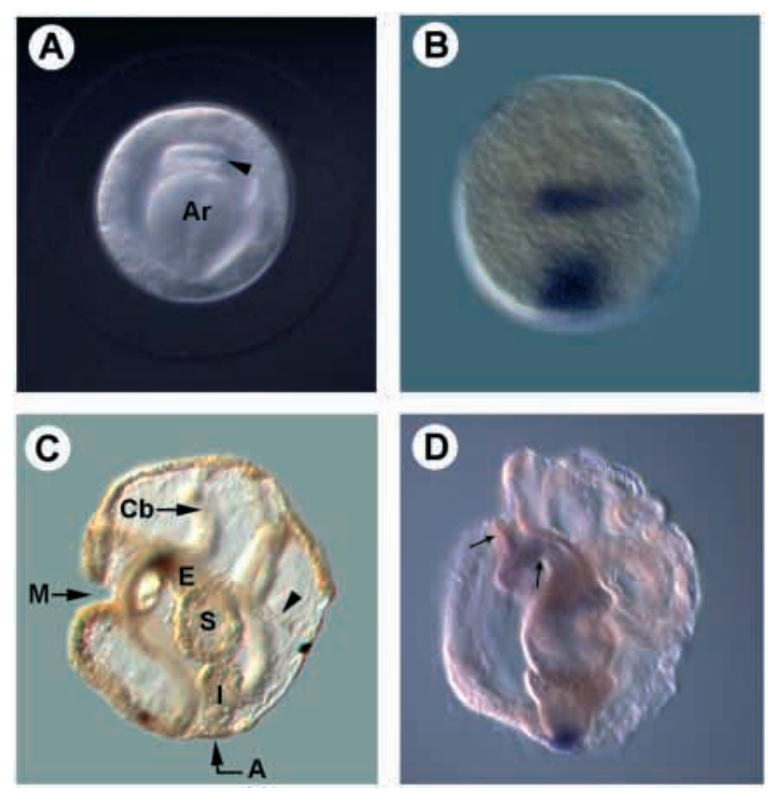

Fig. 3. Early development and spatial expression pattern of PfBra in embryonic- and larval-specific tissues. (A) Early gastrula of Ptychodera flava. Note the mesodermal sac (arrowhead) at the top of the archenteron (Ar). The enclosed coelomic cavity is the protocoel. (B) PfBra WMISH of an early gastrula. PfBra is not expressed anywhere in the embryonic mesoderm, but only in the oral and anal regions of the embryonic gut. (C) Photomicrograph of a 1-week tornaria larva. The larva is now complete with a tripartite gut (M, mouth; E, esophagus; S, stomach; I, intestine; A, anus and Cb, ciliated band). The telotroch, the locomotory ciliated band surrounding the anus, is present but not visible in the micrograph. The protocoel is continuous with the surrounding sea water via the pore canal and hydropore; this structure (coelom, canal and pore, indicated by the arrowhead) is the larval protonephridum (Ruppert and Balser, 1986). (D) PfBra WMISH of a 1-week larva. Note the continued expression of PfBra in the anal region of the intestine and in the ventral wall of the esophagus (delineated with arrows). Specimens in A and B measure about $150 \mu \mathrm{m}$ in diameter; C and D about $250 \mu \mathrm{m}$ in length. 
Fig. 4. Photomicrographs of anesthetized Ptychodera flava larvae. (A) Dark-field photomicrograph of a 2-month tornaria larva. Aside from the beginning of ciliated band specializations known as tentacles (Tn), further development of the telotroch (Te) and an increase in size to about $1 \mathrm{~mm}$ in length, there is little morphological difference between this stage and the one-week larva shown in Fig. 3C. The arrowhead points to the larval protonephridium. On the left is an oral view (adult ventral), on the right a side view. At the top of the animal are the two eye spots (Ey). (B) Dark-field photomicrograph of a 3-month larva shown in oral view. By this stage, the larva is about $2 \mathrm{~mm}$ in length and has fully developed tentacles, specializations of the ciliated band used for feeding and found exclusively in Ptychodera species (Hyman, 1959). It is at this stage that the mesocoels and metacoels begin to form from mesenchymal cells (arrows refer to panels $F$ and $G$ ). (C) A 3.5-month larva shown in anal view. The coeloms are now of considerable size and are beginning to circumscribe the gut. Arrowheads point to the metacoels; S, stomach; M, mouth; Te, telotroch. (D) Dark-field photomicrograph of a 4-month tornaria larva. The larva has reached $3 \mathrm{~mm}$ in length, the maximum size obtained in our culture conditions. On the left is a view from the hydropore (adult dorsal aspect); on the right, side view. The coeloms are well developed with the proboscis coelom greatly expanded compared to earlier stages (cf. [A]). Also note the prominent conical bulge in the anal field and the general increase in size of the posterior region of the larva. After this stage (Hadfield, 1975), the larvae decrease in dimension, the tentacles are lost and the ectoderm around the proboscis coelom begins to take the shape of a proboscis (compare with Fig. 5A). (E) Schematic
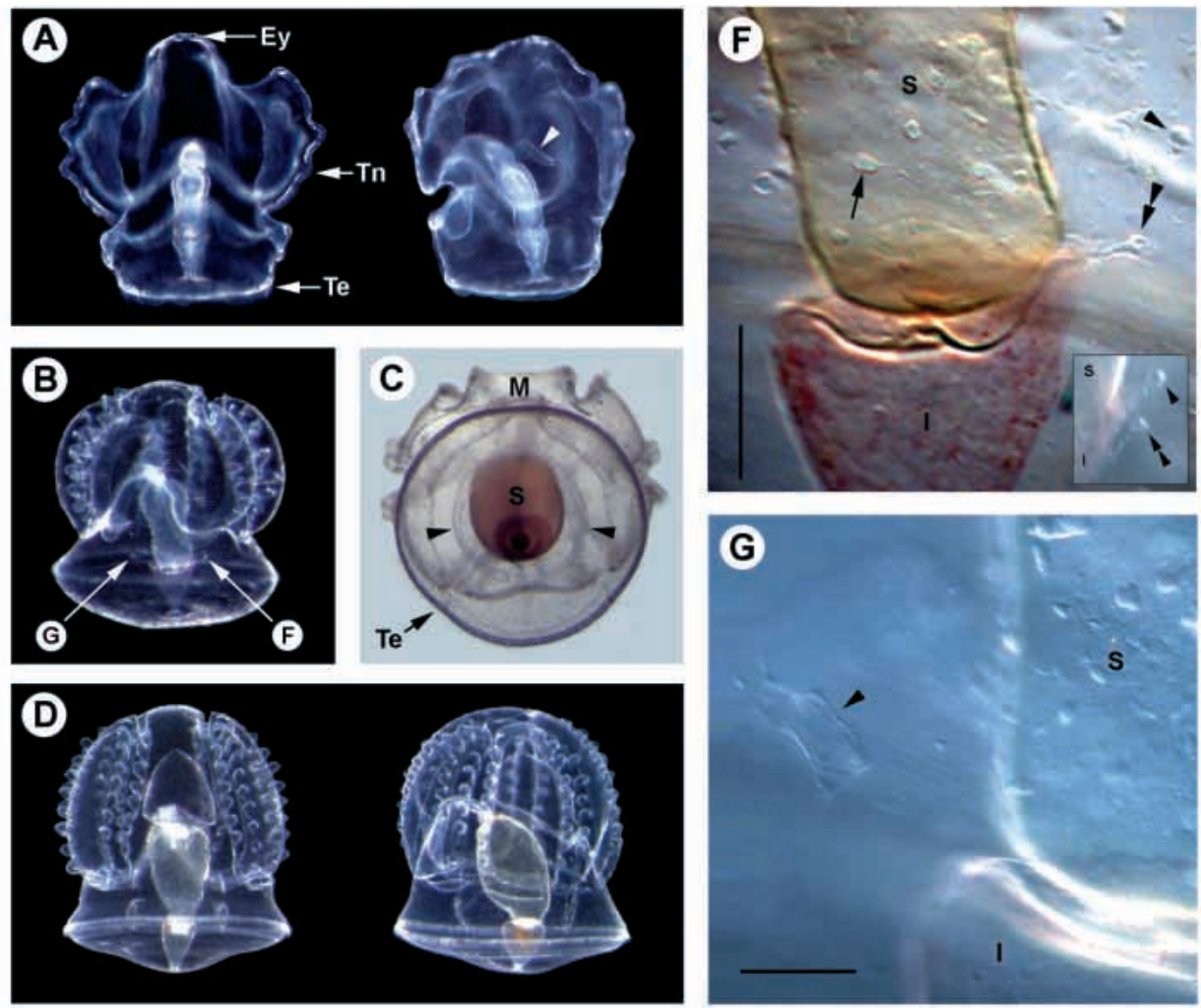

E
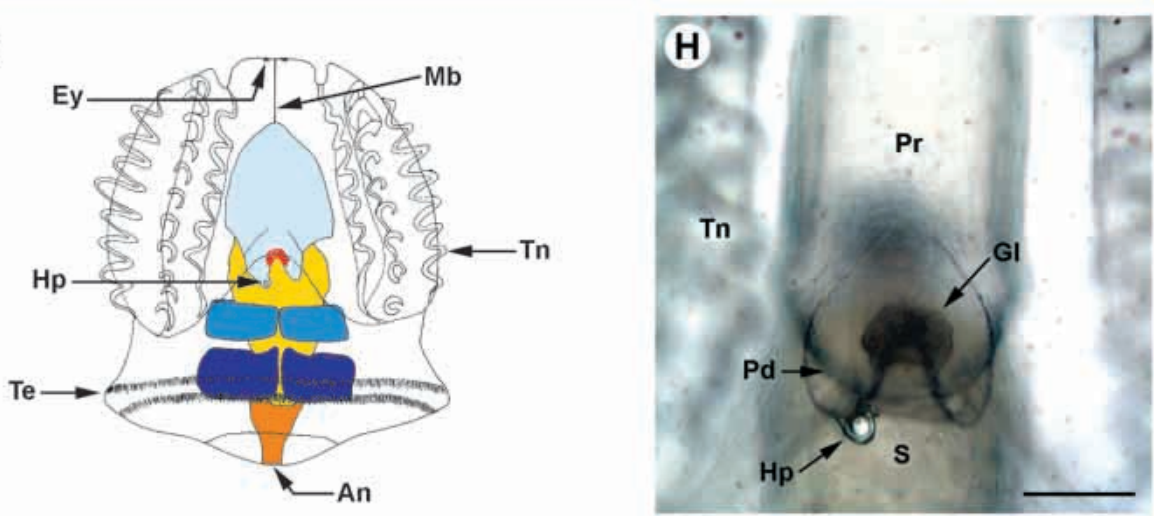
drawing of the dorsal surface of the larva pictured in D. The metacoels are shown in dark blue, the mesocoels in medium blue and the protocoel in light blue. The protocoel is connected to the apical plate, the location of the two eye spots (Ey), by a mesodermal band (Mb). Also indicated is the axial complex with the glomerulus in red and the hydropore $(\mathrm{Hp})$ white (see $[\mathrm{H}]$ for a close-up view of this region of the larva). The stomach is in yellow, the intestine in orange, and the anus (An) indicated on the figure. Ectodermal structures include the tentacles (Tn) and the telotroch (Te). (F) Close up of the left side of the larva shown in B. The double arrowhead is pointing to cells which appear to be delaminating from the gut; S, stomach; I, intestine. Based on their relative position with respect to the stomach/intestine junction, these cells will contribute to the left metacoel. The single arrowhead is pointing to similar cells which will probably contribute to the left mesocoel. The arrow points to one of many mesenchymal cells present in the blastocoel. Scale bar is approximately $200 \mu \mathrm{m}$. The inset shows the same view at a slightly different angle to further illustrate the connection of the coelomic anlagen to the gut. $(\mathrm{G})$ Close up of the right side of the larva shown in B. The arrowhead points to coalescing cells forming the right metacoel. Scale bar is approximately $50 \mu \mathrm{m}$. (H) High magnification photograph of the hydropore and axial complex (see Fig. 1) of a larva at the stage figured in D. The protocoel (Pr) communicates to the exterior via the protocoelomic duct (Pd) and hydropore (Hp). Visible in the midline is the glandular glomerulus $(\mathrm{Gl})$. Tn, tentacle; $\mathrm{S}$, stomach. Scale bar is approximately $250 \mu \mathrm{m}$.

exterior via the ectodermally derived distal duct and hydropore. The coelomic cavity, duct and hydropore form a protonephridium or larval 'kidney' (Ruppert and Balser, 1986).

By 2 months of development, the larvae have increased in size from $250 \mu \mathrm{m}$ to about $1 \mathrm{~mm}$ in length (Fig. 4A). Larval growth consists of an expansion of the blastocoelar space, probably due to a net increase in ectodermal cells as the ciliated band becomes more specialized. Importantly, the epithelia of these larvae are never more than a single cell layer thick, nor is there any apparent addition of new cell types or contribution of mesoderm to the overall size of the larva. This is consistent with what is seen in other primary larva including the pluteus larva of sea urchins (Cameron et al., 1989). The telotroch has also increased in girth; it no longer extends only around the 
Fig. 5. Metamorphosis and adult spatial expression pattern of PfBra. Competent larvae collected out of the plankton will complete metamorphosis when placed on sand. Competent larvae and juveniles were fixed at 24 hour intervals for WMISH. (A-F) Dorsal view with anterior to the top; (G-J) cross sections in which dorsal is to the top. (A) PfBra WMISH of a competent larva from the plankton. Note the formation of the proboscis, which is expressing PfBra. The horizontal dash indicates the plane of section shown in G. The arrowhead indicates the position of the telotroch, which is apparent as a line across the body. (B) Negative (sense) control of the same stage as A. Again the telotroch is indicated with the arrowhead. (C) WMISH of a competent larva 24 hours after contact with sand. The mesosome and metasome are now clearly delineated and both express PfBra. The telotroch (arrowhead) has lost most of its cilia but can still be identified. Horizontal dashes indicate the planes of section shown in H-J. (D) Positive 24-hour control showing the ubiquitous expression of a cytoplasmic actin gene.

(E) WMISH of a 3-day juvenile. All three body regions are still expressing PfBra. The dark spots in the trunk region are ingested sand grains. The arrowhead indicates the relative position of the telotroch. (F) Negative (sense) 72-hour control. (G) Transverse section of the proboscis of the larva shown in A. PfBra is expressed in the mesoderm, specifically the lining of the protocoel (Pr) and the cells delaminating from this lining which will eventually fill most of the coelomic space; these cells are, or are in the process of becoming, the longitudinal musculature of the proboscis (see Fig. 1). (H) Transverse section through the collar region of the larva shown in $\mathrm{C}$. PfBra is strongly expressed in the somatopleura of the mesocoel (Ms) and the cells delaminating from this layer which will form the collar musculature. There may also be expression in the splanchnopleura. Note the histology of the pharynx $(\mathrm{Ph})$; it consists of large vacuolated cells and is histologically very similar to the stomochord (Fig. 5J) (see also Ruppert, 1997). (I) Transverse section of the larva shown in $\mathrm{C}$ through the intestine region. PfBra is expressed in the posterior region of the intestine (I) and the coelomic lining of the metacoel (Mt) (boxed region of the metacoel is shown in the inset). ( $\mathrm{J}$ ) Transverse section of the larva shown in $\mathrm{C}$ through the base of the proboscis.

The stomochord (St) does not express PfBra. However, a group of cells located dorsal to the stomochord are positive for PfBra (arrow); inset shows the same area from the 72-hour animal shown in E. The exact nature of these cells is unclear at this time and was not studied further. The animals figured in $\mathrm{A}$ and $\mathrm{B}$ are about $1 \mathrm{~mm}$ in length; in $\mathrm{C}$ and $\mathrm{D}$ about $1.5 \mathrm{~mm}$ in length; in $\mathrm{E}$ is about $2.5 \mathrm{~mm}$; and in $\mathrm{F}$ about $2 \mathrm{~mm}$ in length. anus, but now surrounds the whole posterior edge of the larva. The ciliated band has begun to generate specializations called tentacles, structures which appear to be limited to the genus Ptychodera within the enteropneusts (Hyman, 1959; Hadfield, 1975). These are first seen as small ridges along the edge of the ciliated band in Fig. 4A. They seem to serve to enhance feeding and may be necessitated by the large size and extended planktonic existence of Ptychodera larvae (Strathmann and Bonar, 1976), though their exact function has not been studied in detail (Gilmour, 1982). Aside from the protonephridium and wandering mesenchyme cells in the blastocoel (see Fig. 4F, and Tagawa et al, 1998b), no other mesoderm is apparent in these larvae.

At 3 months of development tentacles are now evident and there is a further widening of the plane of the telotroch (Fig. 4B). The most important change relevant to this study is the appearance of the mesocoels or collar coeloms and the metacoels or trunk coeloms. These arise from cells which appear to delaminate from the gut (Fig. 4F) and coalesce to form the bilateral mesodermal sacs (Fig. 4G). In contrast to other indirectly developing hemichordates (summarized in Hadfield, 1975), both pairs of coeloms form at the same time, following the development of tentacles. Cells that form the metacoels appear to arise from the stomach/intestine junction; those that form the mesocoels arise from the wall of the stomach (Fig. 4F).

After about two more weeks of development the larvae are still expanding in size; a representative animal measures about $2.5 \mathrm{~mm}$ in length (Fig. 4C). The coeloms are conspicuous in the blastocoel and are now beginning to circumscribe the gut (Fig. 4C). Their position contrasts sharply with that described by Morgan (1894) for Ptychodera bahamensis (c.f. Hyman, 
1959), in which the wandering mesenchymal cells aggregate against the epidermis in the position of the presumptive coeloms. Also making their appearance at this stage are the pericardium and glomerulus (Fig. 4H). These structures are components of the axial complex, the metanephridium or adult 'kidney' (see Fig. 1, and Ruppert and Balser, 1986).

At 4 months of development the larvae have reached the maximum size obtained in our culture conditions, about $3 \mathrm{~mm}$ in length (Fig. 4D,E). The tentacles are well developed and the coeloms have further increased in size. The protocoel is now very conspicuous, having taken the shape that will be assumed by the adult proboscis. After this stage, the larvae decrease in size and become more elongate, the tentacles are gradually lost, the gut is shifted posteriorly, and the whole preoral part of the larva is reshaped into a proboscis (Hadfield, 1975). The larvae are competent to undergo metamorphosis when they have completed these morphological changes. We observed the whole process of larval development from the beginning, with the exception of the last stages of proboscis and gut morphogenesis antecedent to acquisition of competence.

We performed WMISH for PfBra on all larval stages figured in Fig. 4. At no time could any signal above background be detected that is attributable to PfBra (data not shown). Expression of this gene is renewed only when the larvae attain metamorphic competence.

\section{Metamorphosis and expression pattern of PfBra in formation of adult body plans}

Competent $P$. flava larvae were collected from plankton tows off Waikiki Beach, Honolulu, Hawaii. Hybridization of PfBra with competent larvae showed expression in the mesoderm of the protosome (Fig. 5A,G), including cells delaminating from the lining of the coelomic cavity and the lining itself. This lining will form the circular musculature of the proboscis and the delaminating cells form the longitudinal musculature (Morgan, 1894; Hyman, 1959). Expression was not seen in the region where the stomochord will form or anywhere else at this stage. The negative (sense) control showed no expression (Fig. 5B).

Competent larvae placed on appropriate sand will complete metamorphosis within 24 hours such that a clear mesosome/metasome distinction is apparent (Fig. 5C). Growth is also observed: most competent larvae will increase in length between $0.5 \mathrm{~mm}$ and $1.0 \mathrm{~mm}$ during the first 24 hours, and this size increase involves the accretion of multilayered structures including those derived from mesoderm, not just a simple increase in blastocoelar space as seen in the monolayered larvae. Because the position of the telotroch is marked with a pigmented band (Hadfield, 1975, 1978; arrowheads in Fig. 5) and its position can be followed for several weeks, it is clear that growth occurs both in front and behind the telotroch, confirming Morgan's (1894) observations. PfBra is now expressed in the mesoderm of the collar and trunk, and continues in the proboscis musculature. A section through the mesosome (Fig. 5H) shows strong expression in the somatopleura of the mesocoel as well as in cells that appear to be delaminating from this layer and forming the collar musculature (see Hyman, 1959). Expression in the splanchnopleura is weak to absent. Expression was also seen in the very posterior region of the metacoelomic somatopleura and in the wall of the gut (Fig. 5I). Note that the anterior limit of expression in both the gut and the mesoderm is coincident. A section through the base of the proboscis is shown in Fig. 5J. It is clear that there is no PfBra expression in the stomochord, nor did stomochordal sections at any other level ever display PfBra expression, over the time period studied, i.e., the period from the onset of metamorphosis (Fig. 5A) through 72 hours postsettlement (Fig. 5E) during which the stomochord forms (Hadfield, 1975; K. J. P., unpublished observations). However, a group of cells dorsal to the stomochord appear positive for PfBra; although they could be cells in the dorsal sac (see Fig. 1), their exact nature is unclear and requires further study. A positive control embryo at this stage shows ubiquitous expression of a cytoplasmic actin gene as expected (Fig. 5D). By 72 hours, juveniles show continued expression of PfBra in the mesoderm of all three body regions and also in the posterior gut (Fig. 5E). Except for a broader

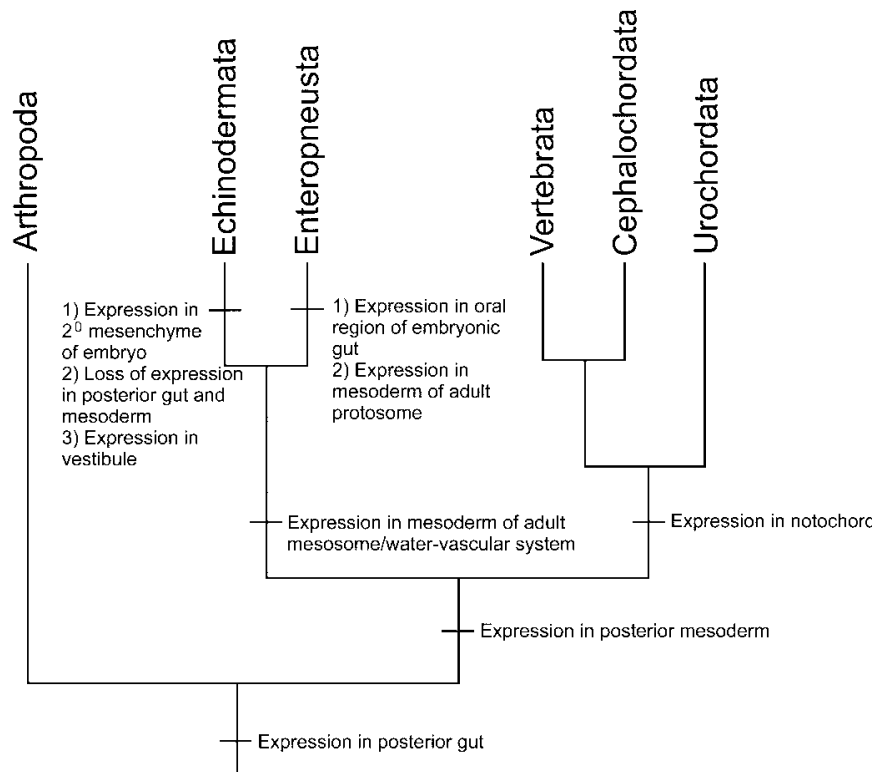

Fig. 6. A proposed evolutionary history of Brachyury utilization, plotted on a diagram displaying phylogenetic relationships of the taxa in which the expression pattern of Brachyury is known (see text for sources of phylogeny). Since Brachyury is expressed in the posterior gut of arthropods, chordates and enteropneusts, this is the primitive role of Brachyury in deuterostomes. We propose that Brachyury was recruited for the specification of mesoderm within the deuterostomes, initially mesoderm of the posterior trunk. In indirectly developing echinoderms and enteropneusts Brachyury has separate embryonic and adult roles. Both phyla share the expression pattern of Brachyury in the mesoderm of the middle coelom (i.e., mesocoel in hemichordates, hydrocoel in echinoderms). Each phylum also shows its own unique adult patterns: The enteropneust expresses Brachyury in the forming mesoderm of the protosome; the euechinoid expresses Brachyury in the vestibule, but has lost expression in the posterior mesoderm (somatocoel derivative) and gut. Brachyury plays unique roles during the embryogenesis of both phyla: it is expressed in the oral region of the hemichordate embryo and is expressed in the secondary mesenchyme of the echinoderm embryo. Within the chordates Brachyury was recruited for the specification of the notochord. Note that in ascidian urochordates the expression in mesoderm has been divided between two paralogues, one expressed in notochord and the other expressed in posterior mesoderm (Yasuo et al., 1996). See text for details and references. 
domain of expression dorsal to the stomochord (Fig. 5J inset), there is little difference in expression between this stage and the 24 hour juvenile figured in Fig. 5C. Hybridization of 48 hour juveniles showed an identical pattern of expression as the 72 hour animals (data not shown). A negative (sense) control again displays no staining (Fig. 5F).

\section{DISCUSSION}

\section{Biphasic expression of PfBra and the process of maximal indirect development}

Ptychodera flava is a hemichordate that undergoes maximal indirect development. This is a phylogenetically widespread mode of development found in many lophotrochozoans (e.g., annelids, entoprocts, ectoprocts, nemerteans), and deuterostomes (echinoderms and enteropneusts), and probably primitive for both clades, but conspicuously absent in the ecdysozoans (e.g., arthropods, nematodes; Peterson et al., 1997; Nielsen, 1998; for discussion of the phylogeny of Bilateria, see Balvoine and Adoutte, 1998). Maximal indirect developers are characterized by the development of a primary larva (Jägersten, 1972), which is the immediate endproduct of embryogenesis and which spends several days to months feeding in the plankton. The adult body plan, which bears little resemblance to that of the larva, is formed from groups of cells that are 'set-aside' from the process of embryonic specification, retaining an indefinite capacity for cell division, in contrast to the embryonic cells that constitute the larva itself (Davidson et al, 1995; Peterson et al., 1997). The process by which $P$. flava generates its adult body plan, as documented in Figs 4 and 5 of this study, is a dramatic illustration of maximal indirect development. We have focused on the mesodermal setaside cell components, here observed for the first time under laboratory conditions, from their appearance in the embryo and feeding larva to their enormous expansion and metamorphic differentiation as the coelomic mesoderm of the juvenile worm.

The significance of the pattern of PfBra expression must be appreciated in terms of its indirect development. That is, early and late patterns belong respectively and exclusively to the embryonic phase when the larval structures are generated, and to the postlarval metamorphic phase when the structures of the adult body are generated. These two phases of expression are separated by months in time. The early phase lasts from midgastrulation through about 10 days of development. The PfBra gene is then downregulated and expression is not detected again until after 5 months of planktonic existence. In these two phases, PfBra is expressed in different cellular components, which largely give rise to different structures. Initially the gene is expressed in the oral and anal regions of the embryonic gut. Ultimately these regions are incorporated in the oral and anal regions of the juvenile. At metamorphosis, however, PfBra is expressed in entirely different cell types, viz. the mesodermal derivatives of each of the three body regions. The only overlap between the embryonic and adult expression patterns is in the posterior gut. The biphasic expression pattern, separated by months in time and located in widely disparate cell types of disparate fate, implies that the Brachyury must have at least two separate $c i s$-regulatory modules, one directing embryonic expression and another expression in the mesoderm of the metamorphic coeloms. Furthermore, it is likely also to have at least two different sets of downstream target genes. Expression of Brachyury is also biphasic in the sea urchin, where its expression again occurs transiently in the embryo, the transcripts disappear, and then reappear in the context of adult body plan formation (K. J. P., unpublished data). We have also studied a second transcription factor, Not, which is similarly utilized in a biphasic manner in the sea urchin (K. J. P., unpublished data). Many other transcription factors, which like Brachyury play developmental roles, are probably also utilized in a biphasic fashion in the process of maximal indirect development (see also Davidson et al., 1995).

The PfBra gene apparently performs several functions during adult body plan formation. First, PfBra is expressed in the posterior gut, the same group of cells (or their progeny) that expressed PfBra in the embryo (see Hyman, 1959). Second, PfBra is probably intimately involved in adult muscle cell specification. PfBra is not detected during the initial stages of endomesodermal set-aside cell delaminations, nor is it expressed at all in the early stages of coelom development. PfBra is detected when cells begin to delaminate from the somatopleura, and both the lining and the delaminating cells are known to form the adult musculature (see Hyman, 1959). The expression of PfBra in body wall muscle cells is consistent with the mode of muscle development in enteropneusts, which are unusual in that the adult muscles are derived from cells that delaminate from the somatopleura (Hyman, 1959). Thus PfBra is expressed in the somatopleura and in the cells delaminating from this lining, but expression is barely observed in the inner lining or splanchnopleura. PfBra may be involved either in specifying the prospective muscle cells of the adult, or in controlling their epithelial-to-mesenchymal transition (Wilson et al., 1995), or both. In addition, PfBra could be involved in both the specification of cells in the dorsal sac (see Fig. 5J) and in morphogenesis. The coincident expression pattern in the posterior mesoderm and intestine in hemichordates is reminiscent of the expression pattern in vertebrates, where functional analysis suggests that Brachyury is involved in axial elongation (see Kispert and Herrmann, 1994).

\section{Evolutionary history of Brachyury utilization}

There now exists sufficient comparative data on Brachyury expression to permit a hypothetical reconstruction of the evolutionary history of Brachyury utilization (Fig. 6). Data from arthropods establishes the primitive role of Brachyury in the latest common ancestor of deuterostomes; i.e., arthropods may be considered the outgroup. The expression pattern of Brachyury has been examined in three insect taxa, Drosophila, Tribolium and Locusta, and all three taxa show expression in the posterior gut and derivatives (e.g., anal pads; Kispert et al., 1994; Murakami et al., 1995; Singer et al., 1996; reviewed in Reuter, 1995). Brachyury is also expressed in the posterior gut of chordates (see Introduction for references) and in enteropneusts, both embryo and adult (Tagawa et al., 1998a; and this work). Thus it is most parsimonious to postulate that the primitive role of Brachyury was specification of the posterior gut.

Brachyury is not expressed in the mesoderm of any arthropod so far examined (Kispert et al., 1994). However, Brachyury was evidently recruited for mesoderm specification at the base of the deuterostomes. We hypothesize that the expression seen in the trunk mesoderm of developing vertebrate embryos is homologous to the expression described 
here in the posterior metacoel of enteropneusts. The coincident expression in gut and mesoderm suggest an inductive relationship between the two (Davidson, 1991). Hence, the link between expression in posterior mesoderm and gut may be a phylogenetically old but intimate one. Nonetheless, this hypothesis demands examination of at least one more outgroup taxon, preferably a member of the Lophotrochozoa (e.g., a polychaete worm).

Within the deuterostomes each major clade recruited Brachyury for the specification of novel mesodermal structures: Chordates recruited Brachyury for the specification of the notochord and in the process must have evolved new cisregulatory apparatus distinct from that directing posterior mesoderm expression (see Clements et al., 1996; Latkinkić) et al., 1997) The latest common ancestor of echinoderms and enteropneusts recruited Brachyury for specification of the mesoderm of the middle coelom or mesocoel (the hydrocoel in echinoderms). This expression in the mesoderm of the mesocoel can be thought of as a shared derived character (i.e., synapomorphy) of Echinodermata + Hemichordata. Each phylum also shows its own unique expression patterns. In echinoderms Brachyury is expressed in secondary mesenchyme of the embryo (Harada et al., 1995; see also K. J. P., unpublished data) and, as indicated in Fig. 6, loss of expression in the posterior mesoderm and gut is inferred from the phylogenetic distribution of the character and the phylogenetic relationship among these taxa. Furthermore, euechinoids express Brachyury in a structure that is unique with respect to other echinoderms, viz. the larval vestibule, which provides the ectodermal component of the adult rudiment, including the anlagen for the adult body wall epithelium and central nervous system (K. J. P., unpublished data). Enteropneusts display a unique pattern of expression in the oral region of the embryonic gut (Tagawa et al., 1998a and this work), and in the mesoderm of the adult protosome, as we show here. The protosome of hemichordates is very muscular and is the primary propulsive organ of the adult. The homologue in echinoderms, on the contrary, plays no role in locomotion and functions solely as an excretory organ.

Thus the evolution of Brachyury utilization took place in many stages. Its evolutionary history illustrates retention of a primitive, pan-bilaterian function, several instances of recruitment in development of phylum-specific structures, and instances of loss of function, some of which are exemplified by the expression pattern of PfBra in Ptychodera flava. This species displays the primitive expression pattern in the posterior gut of both the larva and adult. Recruitment of Brachyury for mesoderm specification, a shared character of the deuterostomes, is seen in the metamorphosing juvenile, where PfBra is expressed in the posterior mesoderm of the metasome. The expression seen in the mesoderm of the mesosome is shared with echinoderms. Finally, the expression seen in the mesoderm of the protosome is unique to enteropneusts. What is compelling about these patterns is that the evolutionary history of the enteropneust body plan is illuminated by the evolutionary history of Brachyury utilization.

\section{The origin of the notochord}

Several authors (e.g., Peterson, 1994; Reuter, 1995; Yasuo et al., 1995; Holland, 1996) have suggested that an examination of the expression pattern of Brachyury might provide a simple test of the proposed homology between the stomochord and notochord (Bateson, 1884). The histological similarity between the two is striking: both are relatively stiff rods consisting of usually vacuolated cells surrounded by a sheath of extracellular material (Welsch and Storch, 1970; Balser and Ruppert, 1990). The primary dissimilarity is that the stomochord is an anterior projection off the dorsal roof of the foregut, as shown in the diagram of the enteropneust body plan provided in Fig. 1. This study shows unequivocally that the stomochord does not express Brachyury, at least during the stages that we examined when the stomochord is developing. The oral expression in the embryo led Tagawa et al. (1998a) to suggest a possible relationship between this pattern of expression and development of the stomochord. However, it is now evident that this embryonic expression pattern is irrelevant to stomochord specification. Expression of PfBra in the embryonic esophagus is ventral, not dorsal; and about 5 months separate the downregulation of embryonic expression and the appearance of the stomochord. Furthermore, PfBra is not expressed in the stomochord in any case. While these results do not support the hypothesis of homology between stomochord and notochord, it is important to emphasize that an absence of expression cannot disprove it. The relationship between the stomochord and notochord could exist at a different level in the specification hierarchy, e.g., downstream, at the level of cell type, or even upstream of Brachyury. A test of this hypothesis would be to examine in the hemichordate expression of a diagnostic downstream target of Brachyury in notochord specification and for stomochord expression of transcription factors such as forkhead that operate upstream of Brachyury in notochord specification (Ang and Rossant, 1994; Weinstein et al., 1994).

We would like to thank Mike Hadfield and the members of his laboratory (Catherine Unabia, Scott Schellhammer and Brian Nedved) for their tireless efforts to make K. J. P.'s trips to the Kewalo Marine Laboratory enjoyable and successful. We would also like to thank Richard Chock for going above and beyond the call of duty to tow for Ptychodera larvae. We also want to thank Bob Turring of the Graphic Arts Facility (Caltech) for drawing Fig. 1 and Vanessa Moy for drawing Fig. 4E. K. J. P. would also like to thank members of the Davidson laboratory, especially Andrew Ransick, for their advice with in situ hybridization. We are grateful to Dr James Coffman of Caltech for review and advice on a draft of this manuscript. This work was supported by grants from the NIH (HD-05753) to E. H. D., and HFSP (RG212/1997) to N. S. and R. A. C.; K. J. P. was supported by a Caltech Molecular Geobiology Fellowship.

\section{REFERENCES}

Ang, Siew-L. and Rossant, J. (1994). $H N F-3 \beta$ is essential for node and notochord formation in mouse development. Cell 78, 561-574.

Balavoine, G. and Adoutte, A. (1998). One or three Cambrian radiations? Science 280, 397-398.

Balser, E. J. and Ruppert, E. E. (1990). Structure, ultrastructure, and function of the preoral heart-kidney in Saccoglossus kowalevskii (Hemichordata, Enteropneusta) including new data on the stomochord. Acta Zool., Stockh. 71, 235-249.

Bateson, W. (1884). Note on later stages in the development of Balanoglossus kowalevskii (Agassiz) and on the affinities of the Enteropneusta. Proc. R. Soc. Lond. B Biol. Sci. 38, 23-30.

Benito, J. and Pardos, F. (1997). Hemichordata. In Microscopic Anatomy of Invertebrates, vol. 15: Hemichordata, Chaetognatha, and in the Invertebrate 
Chordates (ed. F. W. Harrison and E. E. Ruppert), pp. 15-101. New York: Wiley-Liss.

Cameron, R. A., Britten, R. J. and Davidson, E. H. (1989). Expression of two actin genes during larval development in the sea urchin Stronglyocentrotus purpuratus. Mol. Reprod. Dev. 1, 149-155.

Cameron, R. A., Peterson, K. J. and Davidson, E. H. (1998). Developmental gene regulation and the evolution of large animal body plans. Amer. Zool. 38, 609-620.

Castresana, J., Feldmaier-Fuchs, G. and Pääbo, S. (1998). Codon reassignment and amino acid composition in hemichordate mitochondria. Proc. Natl. Acad. Sci. USA 95, 3703-3707.

Church, G. M. and Gilbert, W. (1984). Genomic sequencing. Proc. Natl. Acad. Sci. USA 81, 1991-1995.

Clements, D., Taylor, H. C., Herrmann, B. G. and Stott, D. (1996). Distinct regulatory control of the Brachyury gene in axial and non-axial mesoderm suggests separation of mesoderm lineages early in mouse gastrulation. Mech. Dev. 56, 139-149.

Conlon, F. L., Sedgwick, S. G., Weston, K. M. and Smith, J. C. (1996). Inhibition of Xbra transcription activation causes defects in mesodermal patterning and reveals autoregulation in Xbra in dorsal mesoderm. Development 122, 2427-2435.

Corbo, J. C., Levine, M. and Zeller, R. W. (1997). Characterization of a notochord-specific enhancer from the Brachyury promoter region of the ascidian, Ciona intestinalis. Development 124, 589-602.

Cunliffe, V. and Smith, J. C. (1992). Ectopic mesoderm formation in Xenopus embryos caused by widespread expression of a Brachyury homologue. Nature 358, 427-430.

Danos, M. C. and Yost, H. J. (1996). Role of notochord in specification of cardiac left-right orientation in zebrafish and Xenopus. Dev. Biol. 177, 96-103.

Davidson, E. H. (1991). Spatial mechanisms of gene regulation in metazoan embryos. Development 113, 1-26.

Davidson, E. H., Peterson, K. J. and Cameron, R. A. (1995). Origin of adult bilaterian body plans: Evolution of developmental regulatory mechanisms. Science 270, 1319-1325.

Ding, X., Hausen, P. and Steinbeisser, H. (1998). Pre-MBT patterning of early gene regulation in Xenopus: The role of the cortical rotation and mesoderm induction. Mech. Dev. 70, 15-24.

Edmondson, C. H. (1946). Reef and Shore Fauna of Hawaii. Honolulu: Bernice P. Bishop Museum Special Publication 22.

Eernisse, D. J. (1997). Arthropod and annelid relationships re-examined. In Arthropod Relationships, Systematics Association Special Volume Series 55 (ed. R. A. Fortey and R. H. Thomas), pp. 43-56. London: Chapman \& Hall.

Gilmour, T. H. J. (1982). Feeding in tornaria larvae and the development of gill slits in enteropneust hemichordates. Can. J. Zool. 60, 3010-3020.

Hadfield, M. G. (1975). Hemichordata. In Reproduction of Marine Invertebrates, vol. 2 (ed. A. C. Giese and J. S. Pearse), pp. 185-240. New York: Academic Press.

Hadfield, M. G. (1978). Growth and metamorphosis of planktonic larvae of Ptychodera flava (Hemichordata: Enteropneusta). In Settlement and Metamorphosis of Marine Invertebrate Larvae (ed. Fu-S. Chia \& M. E. Rice), pp. 247-254. New York: Elsevier.

Harada, Y., Yasuo, H. and Satoh, N. (1995). A sea urchin homologue of the chordate Brachyury $(T)$ gene is expressed in the secondary mesenchyme founder cells. Development 121, 2747-2754.

Herrmann, B. G. (1995). Introduction: The Brachyury gene. Sem. Dev. Biol. 6, 381-384.

Herrmann, B. G. and Kispert, A. (1994). The $T$ genes in embryogenesis. Trends Genet. 10, 280-286.

Herrmann, B. G., Labeit, S., Poustka, A., King, T. R. and Lehrach, H. (1990). Cloning of the $T$ gene required in mesoderm formation in the mouse. Nature 343, 617-622.

Holland, N. D. (1996). Homology, homeobox genes, and the early evolution of the vertebrates. Mem. Cal. Acad. Sci. 20, 63-70.

Holland, L. Z., Holland, P. W. H. and Holland, N. D. (1996). Revealing homologies between body parts of distantly related animals by in situ hybridization to developmental genes: Amphioxus to vertebrates. In Molecular Zoology: Advances, Strategies, and Protocols (ed. Ferraris, J. D. \& Palumbi, S. R.). pp. 267-282. New York: Wiley-Liss.

Hyman, L. H. (1959). The Invertebrates, vol. 5, Smaller Coelomate Groups. New York: McGraw Hill.

Jägersten, G. (1972). Evolution of the Metazoan Life Cycle: A Comprehensive Theory. London and New York: Academic Press.

Kavka, A. I. and Green, J. B. A. (1997). Tales of tails: Brachyury and the Tbox genes. Biochim. Biophys. Acta 1333, F73-F84.
Kim, S. K., Hebrok, M. and Melton, D. A. (1997). Notochord to endoderm signaling is required for pancreas development. Development 124, 42434252.

Kispert, A. and Herrmann, B. G. (1994). Immunohistochemical analysis of the Brachyury protein in wild-type and mutant mouse embryos. Dev. Biol. 161, 179-193.

Kispert, A., Herrmann, B. G., Leptin, M. and Reuter, R. (1994). Homologs of the mouse Brachyury gene are involved in the specification of posterior terminal structures in Drosophila, Tribolium, and Locusta. Genes Dev. 8 , 2137-2150.

Kispert, A., Koschorz, B. and Herrmann, B. G. (1995). The T protein encoded by Brachyury is a tissue-specific transcription factor. EMBO J. 14, 4763-4772.

Knezevic, V., De Santo, R. and Mackem, S. (1997). Two novel chick T-box genes related to mouse Brachyury are expressed in different, nonoverlapping mesodermal domains during gastrulation. Development 124, 411-419.

Latinkić, B., Umbhauer, M., Neal, K. A., Lerchner, W., Smith, J. C. and Cunliffe, V. (1997). The Xenopus Brachyury promoter is activated by FGF and low concentrations of activin and suppressed in high concentrations of activin and by paired-type homeodomain proteins. Genes Dev. 11, 32653276.

Morgan, T. H. (1891). The growth and development of tornaria. J. Morphol. 5, 407-458.

Morgan, T. H. (1894). The development of Balanoglossus. J. Morphol. 9, 186.

Murakami, R., Shigenaga, A., Kawakita, M., Takimoto, K., Yamaoka, I., Akasaka, K. and Shimada, H. (1995). aproctous, a locus that is necessary for the development of the proctodeum in Drosophila embryos, encodes a homolog of the vertebrate Brachyury gene. Roux's Arch. Dev. Biol. 205, 8996.

Nielsen, C. (1995). Animal Evolution: Interrelationships of the Living Phyla. Oxford: Oxford University Press.

Nielsen, C. (1998). Origin and evolution of animal life cycles. Biol. Rev. Camb. Philos. Soc. 73, 125-155.

O'Reilly, M.-A. J., Smith, J. C. and Cunliffe, V. (1995). Patterning of the mesoderm in Xenopus: Dose-dependent and synergistic effects of Brachyury and Pintallavis. Development 121, 1351-1359.

Papaioannou, V. E. (1997). T-box family reunion. Trends Genet. 13, 212 213.

Papaioannou, V. E. and Silver, L. M. (1998). The T-box gene family. BioEssays 20, 9-19.

Pardos, F. and Benito, J. (1988). Blood vessels and related structures in the gill bars of Glossobalanus minutus (Enteropneusta). Acta Zool., Stockh. 69, 87-94.

Peterson, K. J. (1994). Understanding chordate origins: testing hypotheses of homologous structures between chordates and enteropneusts. Am. Zool. 34, Addendum, 10AA.

Peterson, K. J. (1995). A phylogenetic test of the calcichordate scenario. Lethaia 28, 25-38.

Peterson, K. J., Cameron, R. A. and Davidson, E. H. (1997). Set-aside cells in maximal indirect development: Evolutionary and developmental significance. BioEssays 19, 623-631.

Ransick, A., Ernst, S., Britten, R. J. and Davidson, E. H. (1993). Whole mount in situ hybridization shows Endo16 to be a marker for the vegetal plate territory in sea urchin embryos. Mech. Dev. 42, 117-124.

Rao, K. P. (1954). The early development of an Enteropneusta Ptychodera flava Eschscholtz. J. Zool. Soc. India 6, 145-152.

Reuter, R. (1995). The T-related gene (Trg), a Brachyury homologue in insects. Sem. Dev. Biol. 6, 427-435.

Ruppert, E. E. (1997). Introduction: Microscopic anatomy of the notochord, heterochrony, and chordate evolution. In Microscopic Anatomy of Invertebrates, vol. 15: Hemichordata, Chaetognatha, and in the Invertebrate Chordates (ed. F. W. Harrison and E. E. Ruppert), pp. 15-101. New York: Wiley-Liss.

Ruppert, E. E. and Balser, E. J. (1986). Nephridia in the larvae of hemichordates and echinoderms. Biol. Bull. 171, 188-196.

Ruppert, E. E. and Barnes, R. D. (1994). Invertebrate Zoology, 6th ed. Fort Worth: Saunders College Publishing.

Schulte-Merker, S., Ho, R. K., Herrmann, B. G. and Nüsslein-Volhard, C. (1992). The protein product of the zebrafish homologue of the mouse $T$ gene is expressed in nuclei of the germ ring and the notochord of the early embryo. Development 116, 1021-1032.

Schulte-Merker, S., van Eeden, F. J. M., Halpern, M. E., Kimmel, C. B. 
and Nüsslein-Volhard, C. (1994). no tail (ntl) is the zebrafish homologue of the mouse T (Brachyury) gene. Development 120, 1009-1015.

Singer, J. B., Harbecke, R., Kusch, T., Reuter, R. and Lengyel, J. A. (1996). Drosophila brachyenteron regulates gene activity and morphogenesis in the gut. Development 122, 3707-3718.

Smith, J. (1997). Brachyury and the T-box genes. Curr. Opin. Genet. Dev. 7 , 474-480.

Smith, J. C., Price, B. M. J., Green, J. B. A., Weigel, D. and Herrmann, B. G. (1991). Expression of a Xenopus homolog of Brachyury $(T)$ is an immediate-early response to mesoderm induction. Cell 67, 79-87.

Stott, D., Kispert, A. and Herrmann, B. G. (1993). Rescue of the tail defect of Brachyury mice. Genes Dev. 7, 197-203.

Strathmann, R. and Bonar, D. (1976). Ciliary feeding of tornaria larvae of Ptychodera flava (Hemichordata: Enteropneusta). Mar. Biol. 34, 317-324.

Tadano, T., Otani, H., Taira, M. and Dawid, I. B. (1993). Differential induction of regulatory genes during mesoderm formation in Xenopus laevis embryos. Dev. Gen. 14, 204-211.

Tagawa, K., Humphreys, T. and Satoh, N. (1998a). Novel pattern of Brachyury gene expression in hemichordate embryos. Mech. Dev. 75, 151155.

Tagawa, K., Nishino, A., Humphreys, T. and Satoh, N. (1998b). The spawning and early development of the Hawaiian acorn worm (Hemichordata), Ptychodera flava. Zool. Sci. 15, 85-91.

Turbeville, J. McC., Schultz, J. R. and Raff, R. A. (1994). Deuterostome phylogeny and the sister group of the chordates: evidence from molecules and morphology. Mol. Biol. Evol. 11, 648-655.
Wada, H. and Satoh, N. (1994). Details of the evolutionary history from invertebrates to vertebrates, as deduced from the sequences of $18 \mathrm{~S}$ rDNA Proc. Natl. Acad. Sci. USA 91, 1801-1804.

Wattler, S., Russ, A., Evans, M. and Nehls, M. (1998). A combined analysis of genomic and primary protein structure defines the phylogenetic relationship of new members of the T-box family. Genomics 48, 24-33.

Weinstein, D. C., Ruiz i Altaba, A., Chen, W. S., Hoodless, P., Prezioso, V. R., Jessell, T. M. and Darnell, J. E. J. (1994). The winged-helix transcription factor $H N F-3$ is required for notochord development in the mouse embryo. Cell 78, 575-588.

Welsch, U. and Storch, V. (1970). The fine structure of the stomochord of the enteropneusts Harrimania kupfferi and Ptychodera flava. Z. Zellforsch. Mikrosk. Anat. 107, 234-239.

Wilkinson, D. G., Bhatt, S. and Herrmann, B. G. (1990). Expression pattern of the mouse $T$ gene and its role in mesoderm formation. Nature $\mathbf{3 4 3}, 657$ 659.

Wilson, V., Manson, L., Skarnes, W. C. and Beddington, R. S. P. (1995). The $T$ gene is necessary for normal mesodermal morphogenetic cell movements during gastrulation. Development 121, 877-886.

Yasuo, H., Harada, Y. and Satoh, N. (1995). The role of $T$ genes in the organization of the notochord during chordate evolution. Sem. Dev. Biol. 6 , 417-425.

Yasuo, H., Kobayashi, M., Shimauchi, Y. and Satoh, N. (1996). The ascidian genome contains another T-domain gene that is expressed in differentiating muscle and the tip of the tail of the embryo. Dev. Biol. 180 , 773-779. 